\title{
Petersburgo: personagem atuante em Crime e Castigo
}

\section{Edelcio Américo*}

Resumo: O artigo tem por objetivo abordar a presença de São Petersburgo no romance de Fiódor Dostoiévski, Crime e Castigo, bem como as condições histórico-culturais que precederam a obra. No romance, a cidade pode ser vista não apenas como o palco dos acontecimentos, mas também como um personagem atuante que interfere, de forma ativa, na conduta dos protagonistas. A análise é baseada nos trabalhos de Vladimir Toporov e Iúri Lotman, escritos nos anos 1970-80, que apontam para um texto único, chamado por eles "texto de São Petersburgo", presente em diversas obras literárias de diferentes autores russos.

Palavras-chave: literatura russa; São Petersburgo; Dostoiévski; Iúri Lotman; Vladímir Toporov; cidade como texto.

\begin{abstract}
The article aims to analyze the presence of the city Saint Petersburg in Fyodor Dostoevsky's novel Crime and Punishment, as well as the historical and cultural conditions that preceded this work. In the novel, the city can be seen not only as the stage of events, but also as an active character that interferes actively in the conduct of the protagonists. The analysis is based on the works of Vladimir Toporov and Yuri Lotman, written in 1970-80, which point to a single text, called by them "Saint Petersburg's text", present in many literary works from different Russian authors.
\end{abstract}

Keywords: Russian literature; Saint Petersburg; Dostoevsky; Yuri Lotman; Vladimir Toporov; city as a text.

\footnotetext{
* Doutor em Literatura e Cultura russa pela FFLCH/USP. Professor de língua russa da Universidade Federal do Rio de Janeiro/UFRJ; e-mail: edelcioamerico@yahoo.com.br
} 


\section{Introdução}

Fundada em 1703, nos moldes europeus, pelo arbítrio de Pedro, o Grande, a nova capital, São Petersburgo, tomou o lugar de Moscou e passou a protagonizar diversas obras artísticas. Na literatura, os contrastes que envolvem São Petersburgo chamaram a atenção de vários escritores, entre eles os precursores de Dostoiévski: Aleksandr Púchkin e Nikolai Gógol. Em Dostoiévski eles são acentuados, não só em decorrência da sua visão crítica dos acontecimentos históricos e culturais que envolveram a cidade desde a sua criação, mas também devido ao agravamento do abismo social na própria vida da cidade nos anos 60-70 do século XIX, em um momento de rápido desenvolvimento econômico e, como consequência, urbano do país.

Crime e Castigo costuma ser chamado de "romance de São Petersburgo." Dostoiévski, assim como Raskólnikov, gostava da cidade, mas o seu amor pela capital de Pedro, o Grande era amargo e até mesmo doloroso. A expressão "Petersburgo de Dostoiévski" remete a um lugar escuro e doentio, sendo bem recorrente, porém sem excluir, o reconhecimento das belas formas da capital do norte.

Petersburgo é mostrada em sua obra por meio de sombras e miragens, em uma sensação embriagante onde nada pode ser visto com clareza: seja o futuro da própria cidade, criada por imposição do Imperador, contra a vontade da natureza, seja o destino dos personagens e da Rússia. Os protagonistas são acuados pelo estranho mundo fantasmagórico e trágico da cidade, seus pensamentos são atormentados. Por um lado, Petersburgo é um fundo social no qual se desenrolam os acontecimentos, por outro é um ator que testemunha atos bárbaros como o cometido por Raskólnikov e seu posterior arrependimento.

Para melhor apresentar o processo de personificação de Petersburgo no romance Crime e Castigo me utilizo do conceito da cidade como um texto, introduzido nos estudos literários russos por Vladimir Toporov (2003) e Iúri Lotman (2002) e tema central da minha dissertação de mestrado e tese de doutorado defendidas no âmbito do programa de pós-graduação em Literatura e Cultura russa da FFLCH/USP. O presente artigo é também resultado da comunicação apresentada por ocasião da Conferência Internacional "Dostoiévski: múltiplas perspectivas" realizada pela Seção Brasileira da Sociedade Internacional de Dostoiévski em São Paulo em maio de 2015. 


\section{A cidade}

O processo de fundação e formação das cidades ocupa um lugar especial e único na história universal e na cultura. Essa afirmação diz respeito a todas as cidades do mundo, mas há que se admitir que entre elas existem algumas às quais a consciência humana destina um status especial, não apenas devido ao seu valor histórico-cultural ou histórico-econômico, mas também no tocante a sua semântica e seu significado especial para uma determinada cultura nacional ou até mesmo mundial.

As cidades, desde o aparecimento, são pontos distribuídos no espaço que carregam uma grande tarefa não apenas funcional, mas também semântica. Na tentativa de qualificar e distinguir uma cidade da outra, somos levados a tentar determinar aquilo que melhor a caracteriza e que possa despertar uma imagem intensa em qualquer observador. A ideia é traduzir um setor da realidade em linguagem, transformá-lo em texto, isto é, em uma informação codificada, e introduzi-lo na memória coletiva.

Cada ponto dominante é reproduzido na memória e funciona como reminiscência da cidade como um todo em forma de um "texto", devolvendo ao sujeito as sensações vividas anteriormente e funcionando como um estímulo para a personificação da imagem na palavra, nas tintas, nos sons. Desse modo, o texto formado não é a realidade, mas sim um material para reconstruí-la; não é apenas um gerador de novos significados, mas um condensador da memória cultural. Todos esses aspectos são unidos na ampla compreensão de distinção.

Como qualquer outra cidade, São Petersburgo tem sua própria descrição, seus pontos dominantes, que interagem conosco, são eles: as ruas, praças, águas, ilhas, jardins, prédios, monumentos, pessoas, história, ideias e podem ser entendidos de maneira heterogênea de acordo com o nível de conhecimento do interlocutor no tocante à cidade.

\section{História versus fantástico}

A explicação da presença do fantástico na formação da imagem de São Petersburgo está no início da história da cidade, na sua milagrosa fundação e na figura de seu fundador-demiurgo Pedro, o Grande. Conforme observa Vladímir Toporov: 
O mal estava na violação das leis da natureza, do bom senso, da vida humana, dessa forma o "mau" começo perpassa toda a história de Petersburgo, do início ao fim. Esse "mau” começo, sem dúvida, explica em muito o tema infernal de São Petersburgo (TOPOROV, 2003, p. 47).

Lotman aponta para a mesma interpretação no tocante à fundação de São Petersburgo:

Essa cidade, criada contra a vontade da natureza, encontra-se em conflito com a mesma, o que permite uma possibilidade dupla de interpretação da cidade: como vitória do intelecto sobre os elementos naturais, de um lado, e como perversão da ordem natural do outro (LOTMAN, 2002, p. 209).

No inconsciente popular, Petersburgo pode até representar o centro do mal e do crime, onde o sofrimento superou quaisquer limites e gravou-se de modo irreversível; igualmente representar um abismo, um reino "estranho", a morte. Porém, Petersburgo é também foi o palco de grandes conquistas culturais. O verdadeiro significado de São Petersburgo, o seu grande papel trágico, está justamente na antítese e antinomia, que coloca a própria morte como base da nova vida. Segundo Toporov:

A nenhuma cidade russa foram dirigidas tantas maldições, injúrias, desmascaramentos, insultos, recriminações, ofensas, lamentos, choros, desencantamentos, quanto a Petersburgo; o texto de São Petersburgo é excepcionalmente rico de representantes desse tratamento "negativo" para com a cidade, o que de maneira alguma exclui (e frequentemente supõe) fidelidade e amor (TOPOROV, 2003, p. 11).

A história de São Petersburgo, conforme observado por Toporov, é vista como fechada, pois se existe o mito de criação, há, em contrapartida, o mito sobre o seu fim. O mito da criação conta como do caos foi formado o cosmos, do inferno, o "paraíso", vide a Petersburgo de Pedro. O mito do fim determina o tema central da mitologia petersburguesa. Esse fim não está em algum lugar longínquo, ele está aqui e agora, pois 
a ideia do fim tornou-se a essência da cidade, ingressou em sua consciência. E essa consciência da catástrofe, provavelmente, é pior que a própria catástrofe.

A consciência da catástrofe antes que essa última se realize coloca diante do homem o problema da escolha, o qual ele não pode evitar. A tradição folclórica ou, mais precisamente, a "tradição popular" insistia de maneira firme no final inevitável de São Petersburgo desde a sua fundação, ou mesmo antes dela (TOPOROV, 2003, p. 41-42).

O mito escatológico de Petersburgo narra como o cosmos se dissolve em caos, é superado por ele; esse caos, geralmente, é representado pela água. Tudo que antes, de certa forma, organizava o espaço da cidade - tanto as águas majestosas e célebres do Neva, quanto os riozinhos pequenos "caseiros" e aconchegantes - passam a adquirir cada vez mais traços relacionados ao abismo, ao mundo inferior, a morte.

Nesse quesito, a história parecia confirmar as profecias que apontavam para Petersburgo como um lugar incompatível com a vida:

O papel das condições climáticas na eliminação da vida das pessoas em Petersburgo era muito significativo: muitos que vieram para a cidade não conseguiram se adaptar às condições climáticas naturais e morriam devido a resfriados, pneumonias, tísicas ou simplesmente devido a queimaduras causadas pelo frio, fato sobre o qual testemunha a imprensa petersburguesa (TOPOROV, 2003, p. 31).

Consequentemente, a própria Petersburgo, também de forma metafórica, podia ser considerada como uma fábrica de mortes. Conforme relatos da época, a preponderância da mortalidade sobre a natalidade geralmente era acentuada.

Além da oposição entre a vida e a morte, Toporov aponta para a correlação entre natureza e cultura. A natureza pode se manifestar como água, chuva, sujeira, umidade, serração, neblina, escuridão, frio, abafamento que se contrapõem ao sol, pôr do sol, suavidade das águas, árvores, frescor, já no que diz respeito à cultura temos estruturas de moradia irregulares, miseráveis ou repugnantes, um quarto-caixão, um cômodo lastimável; uma travessa barulhenta, um "buraco", fedor, sujeira, poeira, gritos, risadas, abafamento; contrapostos a elementos como a avenida, praça, marginal, ilha, a casa de 
campo, cúpula. Em alguns casos, nada é claramente visível por causa da neblina, já em outros, uma vastidão se abre, tudo se preenche com frescor, o pensamento tem a possibilidade de se desenvolver.

Sendo assim, é possível visualizar situações tipicamente petersburguesas: de um lado, um caos dominado pelo escuro e fantasmagórico, no qual nada pode ser visto com claridade, o conceito existente e o não existente trocam de lugares, se misturam e se juntam para confundir o observador (nas obras literárias tal motivo é mais perceptível na forma de miragens, sonhos, fantasmas, sombras, sósias, reflexos nos espelhos, em suma, "diabruras petersburguesas"); e, de outro lado, um cosmos claro e transparente, como uma união ideal da natureza e cultura, caracterizado pela lógica e harmonia.

Os conceitos de "fantasmagórico" e "transparente" são apresentados por Toporov como essenciais para a caracterização da cidade Petersburgo como texto em geral, e mais especificamente no romance Crime e Castigo. Essas definições relacionadas a Petersburgo tornam-se extremamente próximas: assim se inicia um jogo com o leitor que é introduzido no mundo das ilusões. O texto de Petersburgo, dessa forma, torna-se adaptado de maneira ideal a "encenar" uma imprecisão, duplicidade de sentido, estado fantasmagórico.

O substrato espiritual e cultural possui um significado especial no texto de São Petersburgo: mitos e lendas, adivinhações e profecias, obras literárias e monumentos artísticos, ideias filosóficas, sociais e religiosas, as figuras do período petersburguês da literatura russa e personagens literários, todas as variantes de espiritualização e humanização da cidade (TOPOROV, 2003, p. 34).

Cada "palco" de Petersburgo, seja ele a avenida Niévski, parte pomposa e "palaciana" de São Petersburgo, ou os subúrbios possuía seu mito. Havia a São Petersburgo de Pedro, o Grande, que desempenha o papel do Deus implicitus, invisivelmente presente em sua criação, e havia também a Petersburgo do funcionário, do pobre, do "homem fora da cidadania" da cidade.

A face fantasmagórica e teatral de Petersburgo foi abordada igualmente por Iúri Lotman:

A teatralidade do espaço petersburguês era refletida na sua divisão nas partes: "Cênica" e "de bastidores", a consciência constante da presença 
do espectador e o que é mais importante, a troca da existência pela "pseudoexistência": o espectador está sempre presente, porém, para os participantes da ação cênica, é como se ele "não existe": Notar a sua presença significa violar as regras do jogo... A necessidade de plateia representa o paralelo semiótico àquilo que em relação geográfica dá o posicionamento excêntrico do espaço... A constante oscilação entre a realidade do espectador e a realidade do palco; sendo que cada uma dessas realidades, do ponto de vista da outra é apresentada como ilusória, gera o efeito petersburguês de teatralidade (LOTMAN, 2002, p. 216).

Petersburgo sempre se mostrou como uma cidade de contrastes. Os luxuosos palácios que rodeavam a cidade, o brilho da corte imperial, os prédios, que apareciam cada vez em maior quantidade, coexistiam com a extrema pobreza do povo.

Sendo a capital do país, a cidade apresentava características interessantes, por ter sido criada e povoada inicialmente por estrangeiros de diversas origens; além disso, por ter sido desde o início uma cidade voltada para a atividade administrativa, cultural e etc., as moradias eram poucas. Tudo isso resultava em superpopulação. Por exemplo, na primeira década do século XX, em uma única casa em São Petersburgo viviam em média 70 pessoas, bem acima de qualquer outra média europeia. Outro fator relevante da estrutura petersburguesa era um predomínio da população masculina sobre a feminina. No início do século XIX as mulheres em Petersburgo representavam apenas $30 \%$ da população. Como consequência, a maior porcentagem da população era de homens solteiros e sem filhos, o que acentuava a prática da prostituição. Os miseráveis, desabrigados e criminosos também eram feridas de Petersburgo, sendo retratados em várias obras literárias, e, inclusive, em Crime e Castigo.

O fato histórico da prostituição é retratado na personagem Sônia Marmeládova. Além disso, segundo Toporov (p. 31), na década de 70 do século XIX, São Petersburgo era a cidade russa com maior incidência de doenças venéreas, alcoolismo (como exemplo, podemos citar o pai de Sônia, o ex-funcionário público Marmeládov que arruinou sua vida em decorrência da bebida), problemas psiquiátricos e suicídios, predominantemente entre as mulheres. A condição doentia de Raskólnikov também parece ser reflexo das características acima mencionadas. 


\section{Petersburgo-personagem}

Em Dostoiévski, a cidade parece captada pela câmera de um diretor de cinema focando todos os seus planos. Há mudanças das tomadas, dos planos; o herói frequentemente é apresentado em diversas posições, o que torna possível ver a situação pelos olhos dos personagens. No trecho abaixo é possível sentir a angústia do personagem Raskólnikov tanto a partir da perspectiva externa, quanto interna, como se o leitor fizesse parte do personagem:

O sentimento de asco sem fim, que começara a oprimir-lhe e angustiarlhe o coração já no momento em que ele apenas caminhava para a casa velha, chegava agora a tais proporções e assumia tamanha nitidez que ele não sabia o que fazer de sua melancolia. Caminhava pela calçada como um bêbado, sem notar os transeuntes e esbarrando neles (DOSTOÍEVSKI, 2001, p. 26).

Para Dostoiévski, a cidade vive uma vida humana: acorda, sorri, se enerva, sente frio, adoece; suas estátuas podem ganhar vida; as janelas dos edifícios agem como olhos que tudo observam, que perseguem os personagens em suas andanças.

São Petersburgo, para a criação artística de Dostoiévski, inicialmente é o local onde se desenrolam as ações dos personagens, já depois que os "defeitos" da sociedade, são apresentados, a cidade passa a influenciar os personagens.

Dostoiévski cria uma imagem concreta da cidade em um período igualmente concreto, com precisão topográfica e menções a locais reais e pontos turísticos da cidade. No caso, tal abordagem produz uma sensação de realidade aos fatos narrados. Por outro lado, o autor cria uma atmosfera estranha para uma imaginação consciente que segue o herói: o leitor perde o senso da realidade e deixa de visualizar seus limites. O motivo do calor e sufocamento na verdade são característicos igualmente para o estado tanto do herói, quanto da sociedade. O sufocamento no caso simboliza o desespero dos heróis que transitam pela cidade sem conseguir fugir dessa condição. Em Crime e Castigo, por exemplo, o quarto de Raskólnikov é descrito como extremamente apertado e sujo "quarto-caixão". A sujeira é igualmente uma característica petersburguesa, especialmente nas regiões pobres da cidade: 
Na rua fazia um calor terrível e, para completar, o abafamento, o aperto, cal por toda a parte, madeira, tijolo, poeira, e aquele peculiar mau cheiro de verão tão conhecido de cada petersburguense sem condição de alugar uma casa de campo - tudo aquilo afetou de modo súbito e desagradável os já abalados nervos do jovem. O cheiro insuportável das tabernas, especialmente numerosas nesta parte da cidade, e os bêbados, que apareciam a cada instante, apesar de ser dia útil, completavam o colorido repugnante e triste do quadro (DOSTOIÉVSKI, 2001, p. 20).

Dostoiévski descreve os quadros de pobreza, bebedeira, sofrimento das camadas mais pobres e aborda as questões mais relevantes da Petersburgo contemporânea, em um enfoque diferente daquele apresentado pelos órgãos oficiais: são mostrados os problemas sociais: os abismos existentes entre as camadas sociais. Dessa forma, o autor cria um quadro social concreto da vida da cidade, de seus símbolos. A tradicional imagem de Petersburgo como uma cidade misteriosa ganha traços extremamente realistas:

Nos andares inferiores, ao lado das tabernas, nos pátios sujos e fedorentos dos prédios da praça Siennáia... acotovelavam-se muitos operários da indústria e esfarrapados de toda a espécie. Raskolnikov gostava predominantemente desses lugares... Ali os seus andrajos não chamavam a atenção arrogante, e se podia andar com a aparência que quisesse, sem escandalizar ninguém (DOSTOIÉVSKI, 2001, p. 76).

À parte da imagem majestosa da grande capital, a Petersburgo de Dostoiévski, em obras como Crime e Castigo, manifesta uma atmosfera de sufocamento, a existência triste dos heróis e seus problemas. Petersburgo é o ambiente dos heróis e de onde são tiradas as fontes sociais para a elaboração da teoria dos personagens, de Raskolnikov, por exemplo. A atmosfera da cidade, como mencionado acima, dá um "empurrão" psicológico em Raskolnikov e induz a sua insanidade e as ideias sobre o crime:

Seu tremor nervoso transbordou em um tremor algo febril; chegou até a sentir calafrio; ficou com frio em meio a todo aquele calorão. Como quem faz esforço, começou de modo quase inconsciente, movido por 
alguma necessidade interior, a fixar o olhar em todos os objetos que ia encontrando, como se estivesse em redobrada procura de distração, porém isso lhe saía mal e a todo instante ele caía em meditação. Quando, sobressaltado, tornava a levantar a cabeça e olhava ao redor, esquecia-se no mesmo instante do que estava pensando e até onde se encontrava... A princípio o verde e o frescor agradaram os seus olhos cansados, habituados à poeira da cidade, à cal e aos prédios enormes, que causavam incomodo e oprimiam (DOSTOIÉVSKI, 2001, p. 68-69).

Muitos dos personagens que habitam Petersburgo são sem teto, ou seja, sem um local sequer para o arrependimento. As pessoas andam como uma multidão que nada ouve e nada entende. O homem na cidade se mostra como um ser solitário, desnecessário. Dessa forma, a Petersburgo pode ser vista como a verdadeira razão dessa sensação de desespero que cercava Raskólnikov: “... o coração batia com intensidade, e com intensidade agitavam-se os pensamentos. Enfim, sentiu-se sufocado e apertado naquele cubículo amarelo, parecido com um armário ou baú. A visão e o pensamento pediam amplidão" (DOSTOIÉVSKI, 2001, p. 55). Na citação, a sensação demonstrada é de um personagem como que em um caixão sem ar, o amarelo pode ser entendido como a cor do adoecimento.

Raskolnikov vive na capital abafada, com pátios escuros, escadas escuras, e com um calor sufocante, com acotovelamentos em todos os lugares cal, madeira, pó de tijolo e que o mau cheiro especial, tão familiar. Dostoiévski mostra conhecer esta cidade como seus heróis, a cada passo. No romance é apresentada uma cidade onde é impossível se manter saudável, vigoroso, cheio de energia. Ela sufoca e esmaga. É parceira no crime, ajuda a gerar na alma do Homem ideias e teorias delirantes, sendo ela uma testemunha ocular de pesadelos, crimes, e tragédias humanas.

\section{Considerações finais}

Para Dostoiévski, Petersburgo é uma criação morta, uma violência contra a natureza, cheia de paradoxos e ficção, sendo o ambiente onde coexistem várias camadas da sociedade: os agiotas, os pobres, estudantes, intelectuais, os ricos e aristocratas. Cada uma delas vê a cidade é de diferentes maneiras: para alguns é festiva e divertida, para outros, cinza e sem esperança, amarelada, como um símbolo de doença. 
Da conversa de Raskólnikov com Svidrigáilov, que se desenrola mais no final do romance, é possível extrair todos os conceitos apresentados acima, Svidrigáilov faz uma síntese das características da cidade e das pessoas que nela habitam:

O senhor se denuncia demais, senhor Rodion Románovitch. Veja mais uma coisa: estou convencido de que muita gente em Petersburgo anda falando sozinha. Essa é uma cidade de semiloucos. Se nós tivéssemos ciência, os médicos, juristas e filósofos poderiam fazer estudos valiosíssimos sobre Petersburgo. É raro um lugar em que se encontrem tantas influências sombrias, grosseiras e estranhas sobre a alma humana como em Petersburgo. Só as influências climáticas, o que não significam! Por outro lado, é o centro administrativo de toda a Rússia, e o seu caráter deve refletir-se em tudo. Mas agora não é disso que se trata e sim de que já observei várias vezes à parte. $\mathrm{O}$ senhor sai de casa - ainda mantém a cabeça erguida. Vinte passos depois o senhor já a baixou, e está com as mãos para trás. Olha, e pelo visto já não enxerga nada nem à frente, nem dos lados. Por último começa a mexer os lábios e a falar sozinho, sendo que às vezes solta uma das mãos e declama, finalmente para um pouco no meio do caminho. Isso é ruim. Pode ser que alguém já o observe, além de mim, e isso já é desvantajoso. Para mim é indiferente, não sou que vou curá-lo mesmo, mas o senhor, é claro, me compreende (DOSTOIÉVSKI, 2001, p.476).

O texto de Petersburgo é um poderoso espaço polifônico de ressonância, nas vibrações do qual já há tempo são ouvidas as alarmantes síncopes da história russa e os "maus" sons do tempo que congelam a alma.

O conceito de Petersburgo como texto, como vimos, foi e continua sendo desenvolvido por diversos autores russos, muitos deles preferem destacar em suas criações o lado negativo, sombrio e fantasmagórico da cidade, porém os mesmos não excluem o lado positivo, pois igualmente dedicam obras de elogios a Veneza do Norte, a maravilha da arquitetura, a cidade das pontes, ilhas, canais. Não é a toa que Petersburgo continua sendo considerada a capital cultural da Rússia. Nas palavras de Lotman: 
Pela quantidade de textos, códigos, ligações, associações, pelo volume da memória cultural acumulada no prazo não significativo de sua existência, Petersburgo por direito, pode ser considerada um fenômeno único na civilização mundial. Ao mesmo tempo, assim como a arquitetura petersburguesa, a cultura de São Petersburgo é uma das conquistas nacionais da vida espiritual da Rússia (LOTMAN, 2002, p. 220).

\section{Bibliografia}

DOSTOIÉVSKI, Fiódor. Crime e Castigo [Tradução de Paulo Bezerra]. São Paulo: Editora 34, 2001.

LOTMAN, Iúri. "Simvólika Peterburga i problemy semiótiki góroda" ('Simbologia de São Petersburgo e os problemas da semiótica da cidade"). In: Istoria i tipológuia rússkoi kultúry (História e tipologia da cultura russa). São Petersburgo: Iskússtvo-SPB, 2002, p. 208-221.

TOPOROV, Vladimir. "Peterburg i peterbúrgskii tekst rússkoi literatury" (Petersburgo e o texto de São Petersburgo da literatura russa). In: Peterbúrgskii tekst rússkoi literatúry. Ízbrannyie tryudy (O texto petersburguês da literatura russa. Obras selecionadas). São Petersburgo: Iskússtvo, 2003. 